\title{
Meningkatkan Kecerdasan Linguistik Anak Usia Dini Dengan Menggunakan Buku Language Smart Kids
}

\author{
Amallia Putri Fitriani ${ }^{1}$, Arwendis Wijayanti ${ }^{2}$, Dita Primashanti Koesmadi ${ }^{3}$ \\ 1,2,3 Jurusan Pendidikan Guru Pendidikan Anak Usia Dini, STKIP Modern, Ngawi, Indonesia
}

\section{AR T I C L E I N F O}

Article history:

Received 28 April 2021

Revised 29 April 2021

Accepted 06 Juni 2021

Available online 25 Agustus 2021

Kata Kunci:

Language Smart Kids,

Kecerdasan Linguistik

Keywords:

Language Smart Kids, Linguistic Intelligence

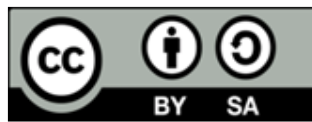

This is an open access article under the CC BY-SA license.

Copyright $(2021$ by Author. Published by Universitas Pendidikan Ganesha.

\begin{abstract}
A B S T R A K
Kecerdasan linguistik merupakan kemampuan untuk menyusun pikirann dengan jelas dan mampu menggunakannya secara kompeten melalui kata-kata untuk mengungkapkan pikiran-pikiran dalam berbicara, membaca, dan menulis. Terdapat beberapa anak yang kurang pada perkembangan linguistik sehingga anak menjadi mudah bosan, kurang memahami huruf, dan anak kesulitan dalam mengeja. Penelitian ini bertujuan untuk meningkatkan kecerdasan linguistik pada anak kelompok B dengan menciptakan buku baca tulis yang berjudul Language Smart Kids. Penelitian yang dilakukan menggunakan metode research and development yaitu dengan metode pengembangan produk baru atau mengembangkan produk yang sudah ada. Uji coba dilakukan pada kelompok kecil dan kelompo besar, pada kelompok kecil dilakukan dengan 5 orang anak sengakan pada kelompok besar dilakukan dengan jumlah 20 anak. Uji kelompok kecil dan kelompok besar dilakukan dengan tiga kegiatan yaitu memahami bahasa reseptif, dapar menggunakan bahasa ekspresik, dan mengenal keaksaraan. Metode pengumpulan data menggunakan wawacara, dan kuesioner. Teknik analisis yang digunakan analisis kuantitatif dan kualitatif. Hasil penilaian yang dilakukan uji kelompok kecil pada kegiatan 1 mendapatkan hasil $100 \%$, kegiatan 2 mendapatkan hasil 85\%, dan kegiatan 3 mendapatkan hasil $95 \%$. Kemudian setalah melakukan uji kelompok kecil, maka dapat melakukan uji kelompok besar pada kegiatan 1 mendapatkan hasil $100 \%$, kegiatan 2 mendapatkan hasil $81,25 \%$, dan kegiatan $88,75 \%$. Maka, buku Language Smart Kids mendapatkan hasil yang sangat baik sehingga buku Laguage smart Kids layak digunakan untuk meningkatkan kecerdasan linguistik anak kelompok B. Implikasi penelitian ini diharapkan buku Language dapat digunakan sebagai pembelajaran disekolah maupun digunakan belajar dirumah.
\end{abstract}

\section{A BS TRACT}

Linguistic intelligence is the ability to organize thoughts clearly and be able to use them competently through words to express thoughts in speaking, reading, and writing. There are some children who lack linguistic development so that children get bored easily, do not understand letters, and children have difficulty spelling. This study aims to improve linguistic intelligence in group $B$ children by creating a reading book entitled Language Smart Kids. Research conducted using research and development methods, namely the method of developing new products or developing existing products. The trial was carried out in small groups and large groups, in small groups with 5 children while in large groups with 20 children. The small group and large group tests were carried out with three activities, namely understanding receptive language, being able to use expressive language, and recognizing literacy. Methods of data collection using interviews, and questionnaires. The analytical technique used is quantitative and qualitative analysis. The results of the assessment carried out by the small group test in activity 1 got 100\% results, activity 2 got $85 \%$ results, and activity 3 got 95\% results. Then after doing the small group test, it can do the large group test in activity 1 getting 100\% results, activity 2 getting $81.25 \%$ results, and $88.75 \%$ activities. So, the Language Smart Kids book got very good results so that the Laguage smart Kids book is suitable to be used to improve the linguistic intelligence of group B children. The implication of this research is that it is hoped that the Language book can be used as learning at school or used to study at home. 


\section{PENDAHULUAN}

Pendidikan Anak usia dini merupakan upaya pembinaan yang ditujukan bagi anak usia 0-6 tahun yang melalui pemberian rangsangan pendidikan untuk membantu pertumbuhan dan perkembangan jasmani rohani supaya anak memiliki kesiapan untuk memasuki pendidikan lebih lanjut (Nurfazrina, 2020; Resti Aulia \& Budiningsih, 2021). Fase anak usia dini merupakan fase yang yang cukup pesat untuk meningkatkan perkembangan kecerdasan, khususnya kecerdasan linguistik anak usia dini sehingga proses perkembangan ini dapat membantu anak dalam beriteraksi (Ananditha, 2017; Novitasari, 2018). Kerdasan linguistik yaitu kecerdasan yang mencangkup dalam aspek bahasa. Kecerdasan linguistik merupakan kecerdasan yang mengolah kata, kemampuan menggunakan kata secara efektif baik secara lisan maupun tertulis (Palenkahu, 2018; Ulwiyah, 2019). Kecerdasan linguistik memiliki empat keterampilan yaitu menyimak, mendengar, menulis, dan membaca. Kecerdasan linguistik merupakan kecerdasan bahasa yang dimiliki anak, kecerdasan ini mencangkup kemampuan individu untuk memproses informasi dan pesan melalui kepekaan terhadap makna, kepekaan terhadap urutan dan bunyi kata, kemampuan untuk menjelaskan, kemampuan daya ingat yang baik dalam menghafal nama dan tanggal, serta kemampuan mendengar cerita atau membaca certita (Ruiyat et al., 2019; Setiantono, 2012; Tanfidiyah \& Utama, 2019). Tujuan mengembangkan kecerdasan lnguistik ini diantaranya adalah anak mampu memberikan penejelasan, dan mampu menjelaskan bahasa itu sendiri (Palenkahu, 2018; Tanfidiyah \& Utama, 2019).

Namun kenyataannya, pada saat ini banyak sekali permasalahan yang terjadi dalam kegiatan baca tulis. Masalah yang terjadi antara lain yaitu anak mudah bosan dan beberapa anak mengalami kesulitan dalam mengingat huruf serta kesulitan dalam mengeja. Metode yang digunakan pendidik satu dengan yang lainyapun berbeda dan menjadi salah satu masalah yang membuat tidak semua anak bisa menerimanya dengan baik. Hal ini sangat berpengaruh sekali pada perkembangan kecerdasan linguistik anak. Namun ada metode yang digunakan hampir semua anak dapat memahaminya pada kegiatan baca tulis ialah dengan menggunakan metode bermain. Kegiatan baca tulis untuk anak usia dini masih menjadi sortan utama dan menjadi perdebatan dalam setiap prektik pendidikan anak usia dini di Indonesia. Beberapa kritik ditujukan kepada sejumlah TK bukan karena mengajarkan membaca, menulis, dan berhitung, melainkan cara yang digunakan salah, seakan-akan menjadikan TK sebagai miniatur SD. Kemampuan pada baca tulis seharusnya tidak diarahkan pada kemampuan akademik, melainkan diarahkan pada kegiatan bermain dan pengenalan yang tentunya juga ditunjang oleh berbagai media pembelajaran yang memadai. Jika permasalahan tersebut dibiarkan akan memberikan dampak buruk bagi pendidikan. Berdasarkan observasi yang telah dilakukan di TK Plus Modern Ngawi, pada saat kegiatan baca tulis berlangsung guru menggunakan metode dan media pembelajaran yang kurang menarik sehingga membuat anak cenderung mudah bosan. Bagaimana cara untuk meningkatkan kecerdasan linguistik anak supaya perkembanganya dapat tercapai ? sesuai dengan observasi dan wawancara yang telah dilakukan, anak mudah bosan, anak kurang memahami huruf serta kesulitan dalam mengeja.

Solusi yang dapat diterapkan yaitu dengan menggunakan media pembelajaran. Media pembelajaran merupakan sumber belajar yang dapat membantu pendidik untuk memperkaya pengetahuan anak-anak. dengan adanya media pembelajaran yang menarik untuk anak akan dapat menjadi rangsangan bagi anak dalam proses pembelajaran (Nur Hidayah \& Nurhadija, 2018; Purnamasari \& Wuryandani, 2019). Bagian integral yang perannya penting pada Taman Kanak-kanak guna menuju kompetensi harapan adalah media pembelajaran. Media pembelajaran berperan penting sebagai wahana untuk mendekatkan persepsi dan pemahaman guru dengan daya tangkap anak (Dewi et al., 2019; Izzaty et al., 2017). Salah satu contoh media pembelajaran yang biasa digunakan pada kegiatan baca tulis dengan media buku, misalnya seperti buku baca tulis. Dengan adanya buku baca tulis ini dapat meningkatkan kecerdasan linguistik pada anak usia dini. Melalui media pembelajaran siswa dapat bermain sambil belajar (Jundu et al., 2019; Sumaryanti, 2020). Bermain merupakan kebutuhan mendasar bagi anak usia dini, dengan cara bermain merasakan kepuasan dalam berbagai hal seperti perkembanagn motorik, kognitif, kreativitas, bahasa, emosi, sosial, dan sikap(Hidayat, 2017; Nasution et al., 2019). Selain itu rangsangan dan latihan dapat dilakukan oleh orang tua dan pendidik secara terus menerus sehingga dapat mengembangkan keterampilan berbahasa anak sekalipun anak tidak memiliki kecerdasan linguistik yang tinggi, walaupun hasilnya tidak sebesar anak yang memiliki kecerdasan linguistik.

Temuan penelitian sebelumnya menyatakan untuk meningkatkan kemampuan membaca menggunakan buku cerita sebagai media pembelajaran untuk pengenalan membaca yang mengacu pada aspek bahasa (Vera Sardila, 2015). Literasi untuk menstimulasi perkembangan kemampuan kemampuan bahasa anak untuk mengenal dan menceritakan bentuk tulisan atau gambar yang terdapat dalam sebuah buku bacaan(Halim, 2019; Izzaty et al., 2017). Penelitian ini dilakukan untuk meningkatkan kecerdasan linguistik serta menumbuhkan minat membaca dan menulis pada anak usia dini (5-6 tahun) melalui buku baca tulis. Menumbuhkan minat baca anak usia dini perlu dilakukan agar menghasilkan sumber daya 
manusia yang berkualitas tinggi. Pada penelitian lain yang dilakukan sama hal nya yang dilakukan oleh penelitian ini, dengan adanya penelitian ini diharapkan dapat meningkatkan minat baca pada anak pada dasarnya dengan membaca anak akan mendapat pengetahuan dan wawasan. Sesuai dengan kondisi tersebut maka penelitian ini dilakukan untuk meningkatkan kecerdasan linguistik anak usia dini dengan menggunakan buku Language Smart Kids.

\section{METODE}

Penelitian ini menggunakan metode pengembangan (research and development) yang merupakan pendekatan penelitian untuk menghasilkan produk baru atau menyempurnakan produk yang telah ada. Pernyataan dari Borg and Gall (1983:772) mendefinisikan penelitian pengembangan sebagai proses untuk mengembangkan dan memvalidasi produk. Penelitian pengembangan ini bertujuan untuk mengimformasikan proses pengambilan keputusan sepanjang pengembangan dari suatu produk menjadi lebih berkembangan dan kemampuan pengembangan untuk menciptakan berbagai hal dari jenis ini pada situasi kedepan. Penelitian dan pengembangan ini dilakukan pada satu lembaga yaitu TK Plus Modern Ngawi dengan menggunakan uji coba kelompok kecil dan besar. Pada uji coba kelompok kecil dengan subjek 5 anak yang terdiri dari 2 anak laki-laki dan 3 anak perempuan, sedangkan pada uji kelompok besar dengan subjek 20 anak yang terdiri dari 11 anak laki-laki dan 9 anak perempuan. Dan tahapan yang akan peneliti gunakan hanyalah langkah 1 sampai dengan 6 langkah yaitu : 1) Melakukan penelitian (analisis potensi dan masalah) dan pengumpulan data/informasi (kajian pustaka, pengamanan kelas, persiapan laporan pokok persoalaan), 2) Menyusun perencanaan berupa penyusunan rancangan produk buku Language Smart Kids (penyusunan aktifitas kecerdasan linguistik, perumusan tujuan dan penentuan urutan pembelajaran), dan untuk evaluasi ahli, 3) Mengembangkan bentuk produk awak berupa "Buku Language Smart Kids" untuk divalidasi dan dievaluasi oleh ahli materi, ahli media pembelajaran anak usia dini dan ahli desain pembelajaran anak usia dini, 4) Melakukan uji coba lapangan permulaan atau uji kelompok kecil terhadap 5 anak kelompok B TK Plus Modern Ngawi, 6) Melakukan uji lapangan utama atau uji kelompok besar dilakukan oleh anak kelompok B TK Plus Modern Ngawi dengan jumlah anak kelompok B 20 anak terdiri dari anak perempuan dan 14 anak laki-laki. Merevisi produk berdasarkan saran-saran hasil uji kelompok besar. Dalam penelitian ini dilakukan validasi ahli pengambilan data dari para ahli akan sangat berguna dalam menyempurnakan produk yang akan dibuat mengingat mereka sudah berpengalaman dalam bidangnya masing-masing. Uji validasi dilakukan oleh orang-orang yang memiliki pengalaman, pengetahuan, dan juga pemahaman dalam materi tersebut. Valodator dalam penelitian ini adalah dosen yang ahli dalam bidang media dan desain pembelajaran serta ahli materi. Kisikisi instrumen tertera pada tabel berikut:

Tabel 1. Kisi-kisi Instrumen Lembar Validasi Pengembangan Buku Language Smart Kids untuk Ahli Materi.

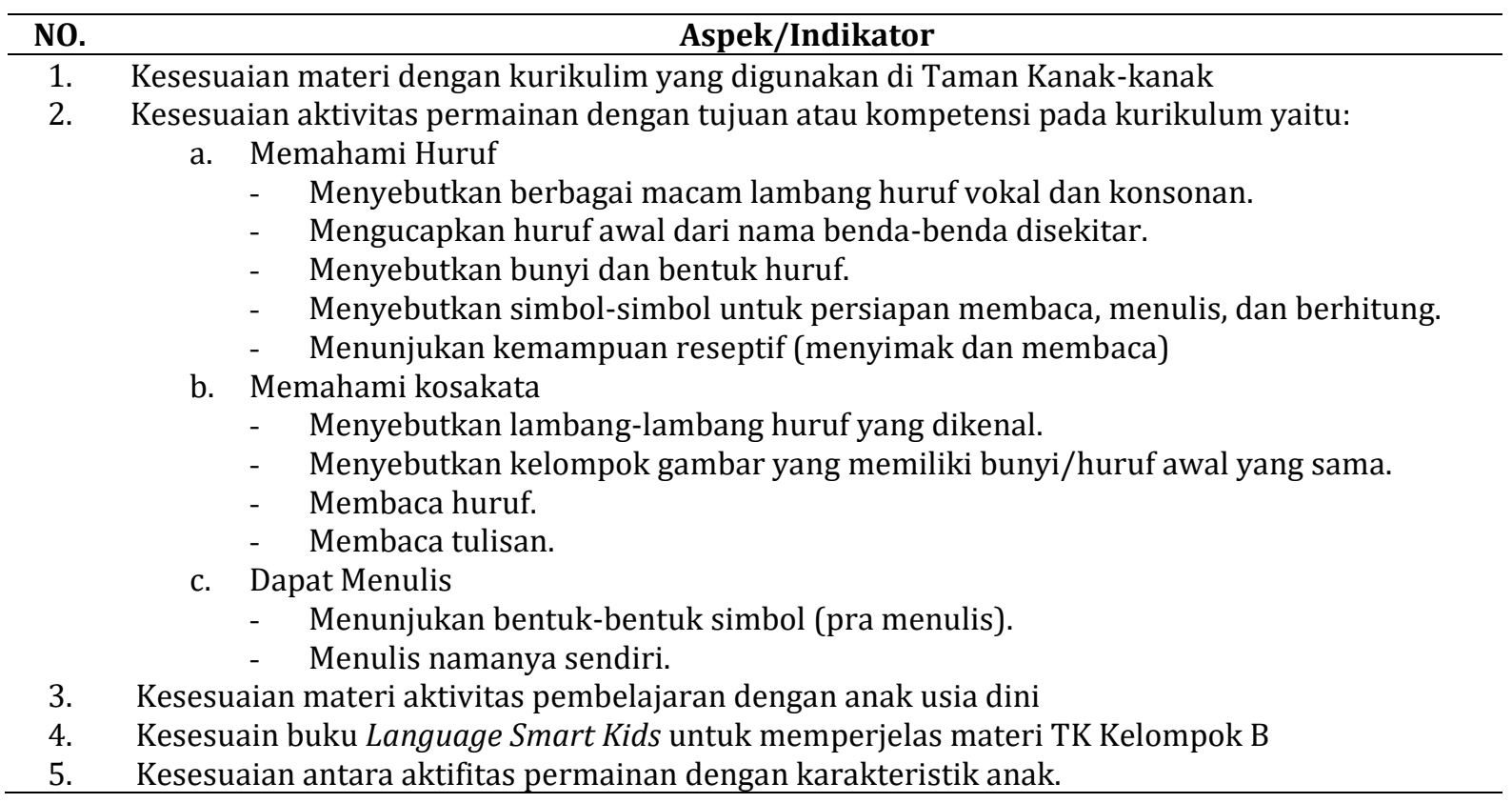


Tabel 2. Kisi-kisi Instrumen Lembar Validasi Pengembangan Buku Language Smart Kids untuk Ahli Media.

\begin{tabular}{|c|c|c|c|}
\hline No & Aspek & No Butir & Indikator \\
\hline \multirow[t]{4}{*}{1} & Segi Fisik & 1 & Kemenarikan buku \\
\hline & & 2 & Jenis bahan yang digunakan \\
\hline & & 3 & Ukuran Buku Language Smart Kids \\
\hline & & 4 & Keawetan atau ketahanan buku Language Smart Kids \\
\hline \multirow[t]{2}{*}{2} & Segi Pemanfaatan & 5 & $\begin{array}{l}\text { Kesesuaian Buku Language Smart Kids jika digunakan anak } \\
\text { Taman Kanak-kanak }\end{array}$ \\
\hline & & 6 & $\begin{array}{l}\text { Kesesuai Buku Language Smart Kids jika dilihat dari segi } \\
\text { kepraktisannya (mudah disimpan, mudah dibawa dan mudah } \\
\text { dipindahkan }\end{array}$ \\
\hline \multirow[t]{3}{*}{3} & Segi Warna & 7 & $\begin{array}{l}\text { Komposisi warna yang digunakan dalam Buku Language Smart } \\
\text { Kids }\end{array}$ \\
\hline & & 8 & $\begin{array}{l}\text { Kesesuaian warna yang digunakan dengan karakteristik anak } \\
\text { Taman Kanak-kanak }\end{array}$ \\
\hline & & 9 & $\begin{array}{l}\text { Warna-warna dalam buku yang digunakan dapat menarik } \\
\text { perhatian anak }\end{array}$ \\
\hline \multirow[t]{2}{*}{4} & Segi Gambar & 10 & Kejelasan gambar \\
\hline & & 11 & Kesesuaian gambar dengan anak Taman Kanak-kanak \\
\hline \multirow[t]{4}{*}{5} & Segi Desain & 12 & Jenis aktifitas buku yang digunakan \\
\hline & & 13 & Jenis huruf dalam buku yang digunakan \\
\hline & & 14 & Ukuran aktivitas buku yang digunakan \\
\hline & & 15 & Ukuran huruf dalam yang digunakan \\
\hline
\end{tabular}

Tabel 3. Kisi-kisi Instrumen Lembar Validasi Pengembangan Buku Language Smart Kids untuk Ahli Desain Pembelajaran.

\begin{tabular}{ll}
\hline No & \multicolumn{1}{c}{ Aspek/Indikator } \\
\hline 1 & Kesesuaian tujuan dengan muatan materi. \\
2 & Kesesuaian langkah-langkah pembelajaran dengan tujuan pembelajaran. \\
3 & Ketepatan langkah-langkah dalam pembelajaran. \\
4 & Ketepatan metode pembelajaran dengan tujuan pembelajaran. \\
5 & Kesesuaian metode dengan langkah-langkah penelitian. \\
6 & Ketepatan pemilihan media dengan tujuan pembelajaran. \\
7 & Ketepatan pemilihan media dengan muatan materi. \\
8 & Ketepatan teknik penilaian pembelajaran. \\
9 & Ketepatan format penilaian pembelajaran. \\
10 & Ketepatan bahan pembelajaran dengan materi pembelajaran. \\
\hline
\end{tabular}

Berdasarkan tabel tersebut merupakan kisi-kisi validasi yang akan digunakan validator untuk memberikan nilai kelayakan pada produk yang dikembangkan. Setelah melalui validasi akan ada beberapa catatan dari validator untuk merevisi produk, agar produk yang dihasilkan lebih menarik dan mudah digunakan untuk anak-anak. Instrumen pengumpulan data yang digunakan dapat penelitian ini dengan menggunakan data kualitatif dan kuantitatif. Pada data kualitatif meliputi saran dan masukan serta tanggapan tentang rancangan produk dari para ahli, analisis kebutuhan melalui wawancara, saran dan masukan serta tanggapan dari guru tentang buku Language Smart Kids. Sedangkan data kuantitatif meliputi hasil evaluasi ahli materi kecerdasan linguistik, hasil evaluasi ahli media pembelajaran, hasil desain pembelajaran, uji coba kelompok kecil, dan uji kelopok besar. Dari hasil data kualitatif dan kuantitatif tersebut dapat menjadi hasil kriteria apakah buku Language Smart Kids layak untuk digunakan atau tidak.

\section{HASIL DAN PEMBAHASAN}

Hasil

Pengumpulan data dari hasil penelitian buku Language Smart Kids pada pembelajaran anak kelompok B TK Plus Modern mengenai meningkatkan kecerdasan linguistik dengan melakukan 3 kegiatan diharapkan mendapatkan hasil yang sempurna. Dengan hasil yang sempurna tersebut dapat menunjukan bahwa buku Language Smart Kids layak digunakan untuk anak kelompok B. Tiga kegiatan yang dilakukan 
sebagai penelitian tersebut antara lain yaitu memahami bahasa reseptif, menggunakan bahasa ekspresif, dan mengenal keaksaraan. Pada uji penelitian ini akan dilakukan dua kali yang pertama uji kelompok kecil dan yang kedua uji kelompok besar. Hasil penilaian uji kelompok kecil dan kelompok besar akan ditunjukan pada grafik 1 . Hasil penilaian yang di dapat anak pada setiap kegiatan menggunakan skala likert dengan rentang nilai terendah 1 dan tertinggi 4, kemudian dalam satu kegiatan penilaian yang dicapai semua anak akan dihitung untuk mendapatkan hasil. Uji coba kelompok kecil dilakukan oleh 5 anak, dengan begitu penilaian yang telah dilakukan pada kegiatan satu mendapatkan $100 \%$, kegiatan dua mendapatkan hasil 85\%, dan kegiatan tiga mendapatkan hasil 95\%. Hasil penilaian yang telah dilakukan pada kelompok kecil mendapatkan hasil yang baik dengan begitu buku Language Smart Kids layak untuk digunakan, namun terdapat saran-saran dari validator dan guru kelas kelompok B sehingga perlu dilakukan untuk merevisi agar buku dapat layak sepenuhnya untuk digunakan. Setelah selesai melakukan revisi sesuai saran maka dapat dilanjutkan dengan uji kelompok besar. Uji coba kelompok besar dilakukan oleh 20 anak maka pada kegiatan satu yang dilakukan mendapatkan hasil 100\%, kegiatan dua mendapatkan $81,25 \%$, dan kegiatan tiga mendapatkan hasil 88,75\%. Dengan hasil yang telah dilakukan pada kelompok besar mendapatkan hasil yang baik sehingga buku Language Smart Kids dapat digunakan pada anak kelompok B untuk mengingkatkan kecerdasan linguistik. Adapun data hasil uji coba kelompok kecil dan kelompok besar mengenai aspek kemudahan, keamanan, dan kesenangan tekait dengan buku Language Smart Kids.Dengan adanya penilaian aspek kemudahan, keamanan, dan kesengangan akan menambah nilai kelayakan pada buku Language Smart kids.

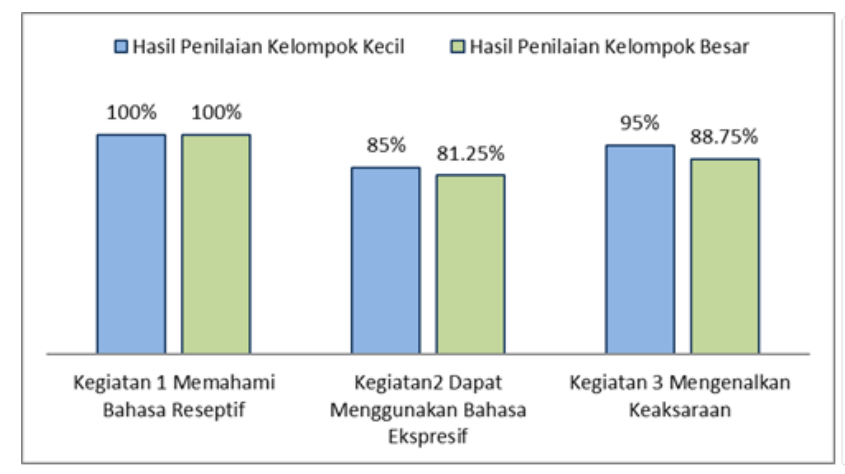

Grafik 1. Hasil Penilaian Uji Kelompok Kecil dan Kelompok Besar.

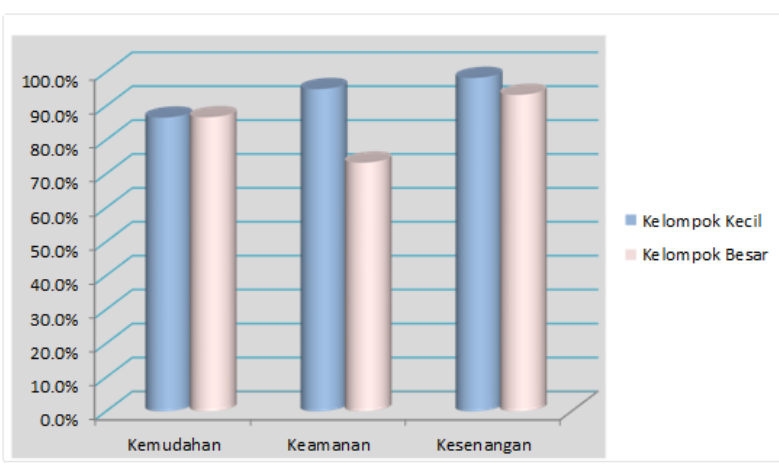

Grafik 2. Hasil uji coba kelompok kecil dan besar terkait tentang aspek kemudahan, keamanan, dan kesengangan.

Berdasarkan dari hasil grafik tersebut mengenai aspek kemudahan, keamanan, dan kesenangan terlihat bahwa uji coba kelompok kecil yang dilakukan oleh 5 orang anak dengan aspek kemudahan mendapatkan hasil penilaian 86,6\%, aspek keamanan mendapatkan hasil penilaian 73,3\%, dan aspek kesenangan mendapatkan hasil penilaian 93,3\%. Kemudian setelah uji coba kelompok kecil dilakukan, selanjutnya uji coba kelompok besar yang dilakukan oleh 20 anak. Pada uji coba kelompok besar terkait aspek kemudahan mendapatkan hasil penilaian $86,6 \%$, aspek keamanan mendapatkan hasil penilaian 95\%, dan aspek kesenangan mendapatkan hasil 96,6\%. Dengan demikian dapat disimpulkan bahwa anakanak kelompok B senang melakukan kegiatan baca tulis dengan menggunakan buku Language Smart Kids.

Penggunaan buku Langugae Smart Kids pada kegiatan baca tulis untuk meningkatkan kecerdasan linguistik anak tergolong sangat efektif. Anak terlihat sangat senang saat kegiatan baca tulis menggunakan buku Langugae Smart Kids. Hal tersebut terlihat pada penilaian yang telah dilakukan pada kelompok kecil dan Kelompok besar. Media buku cerita untuk meningkatkan minat baca anak mengatakan bahwa penggunaan buku cerita terhadap minat baca anak dapat menunjukan perasaan senang pada anak membaca dan ketertarikannya terhadap buku (Hidayah \& Rohmatillah, 2021; Izzaty et al., 2017; Misnawan, 2020). Maka dapat diartikan pada diri anak sehingga dapat mendorong keinginan untuk belajar dan mengetahui isi buku cerita. Menggunakan buku mampu meningkatkan minat bacanya dan dapat memiliki budaya membaca, mampu memperluas wawasannya serta menunjang kwalitas anak dalam dunia pendidikan (Handayani, 2020; Pratiwi, 2017; Surachman, 2020). Selain senang saat kegiatan baca tulis, anak-anak juga mudah untuk memahami huruf, dapat membaca kata dan kalimat dengan mudah kemudian juga saat belajar menulis dengan menebali kata dan kalimat juga memudahkan untuk anak. Metode yang digunakan pada saat kegiatan menarapkan metode bermain sehingga anakpun juga tidak akan mudah bosan dan dapat mengikuti kegiatan dengan baik. Dengan sistem yang tidak menekan secara psikis, dapat menciptakan suasana pemeblajaran yang lebih kondusif dan tidak menegangkan bagi 
anak-anak (Amini \& Suyadi, 2020; Fardiah et al., 2019). Maka dengan begini kecerdasan linguistik anak dapat meningkat sesuai dengan harapan yang diinginkan pendidik dan orang tua. Dengan buku Language Smart Kids maka dapat meningkatkan kecerdasan linguistik selain itu juga dapat meningkatkan minat baca pada anak karena saat anak memiliki minat baca yang sangat tinggi maka akan dapat menambah wawasan.

Temuan ini diperkuat dengan penelitian sebelumnya yang menyatakan buku cerita sebagai media pembelajaran efektif digunakan untuk pengenalan membaca yang mengacu pada aspek bahasa (Vera Sardila, 2015). Buku cerita dapat menstimulasi perkembangan kemampuan kemampuan bahasa anak untuk mengenal dan menceritakan bentuk tulisan atau gambar yang terdapat dalam sebuah buku bacaan (Halim, 2019; Izzaty et al., 2017). Dari pembahasan diatas, buku Language Smart Kids mendapatkan kategori yang sangat baik. Sehinga layak digunakan pada pembelajaran disekolah maupun saat belajar dirumah untuk meningkatkan kecerdasan linguistik anak. Selain itu buku Language Smart Kids dapat memudahkan guru dan orang tua dalam mengajarkan baca tulis anak. Namun terdapat beberapa keterbatasan dalam penelitian misalnya pada saat penelitian kelompok besar, kegiatan berlangsung hanya bisa dilakukan bergantian 5 orang anak saja karena kondisi sekarang ini terjadi akan tetapi penelitian tetap terlaksana sesuai dengan harapan. Implikasi penelitian ini diharapkan dapat membantu siswa dalam meningkatkan kemampuan linguistiknya.

\section{SIMPULAN}

Buku Language Smart Kids mendapatkan kategori yang sangat baik. Sehinga layak dan efektif digunakan pada pembelajaran untuk meningkatkan kecerdasan linguistik anak. Selain itu untuk meningkatkan kecerdasan linguistik anak usia dini dapat menggunakan metode dan media pembelajaran yang menarik supaya kecerdasan linguistik anak dapat terstimulus dengan baik. Buku baca tulis yang dapat difungsikan sebagai peningkatan potensi dalam diri anak.

\section{DAFTAR RUJUKAN}

Amini, N., \& Suyadi, S. (2020). Media Kartu Kata Bergambar Dalam Meningkatkan Kemampuan Kosakata Anak Usia Dini. PAUDIA : Jurnal Penelitian Dalam Bidang Pendidikan Anak Usia Dini, 9(2), 119129. https://doi.org/10.26877/paudia.v9i2.6702.

Ananditha, A. C. (2017). Faktor-Faktor Yang Berhubungan Dengan Perkembangan Motorik Kasar Pada Anak Toddler. Jurnal Keperawatan Muhammadiyah, 2(1). http://repository.umsurabaya.ac.id/id/eprint/2970\%0A.

Dewi, R., Wahyuningsih, S., \& Nurjanah, N. E. (2019). Metode Bercerita Untuk Meningkatkan Kecerdasan Linguistik Anak Usia 4-5 Tahun. Kumara Cendekia, 7(4), 352. https://doi.org/10.20961/kc.v7i4.32092.

Fardiah, Murwani, S., \& Dhieni, N. (2019). Meningkatkan Kemampuan Kognitif Anak Usia Dini melalui Pembelajaran Sains. Jurnal Obsesi: Jurnal Pendidikan Anak Usia Dini, 4(1), 133. https://doi.org/10.31004/obsesi.v4i1.254.

Halim, D. (2019). Dampak Pengembangan Buku Cerita Bergambar Untuk Anak Usia Dini. Jurnal Pendidikan Dan Kebudayaan, 9(3), 203-216. https://doi.org/10.24246/j.js.2019.v9.i3.p203-216.

Handayani, L. (2020). Pengembangan Buku Cerita Berbasis Pendidikan Karakter pada Ranah Sekolah bagi Siswa SMP Kelas VII di Kabupaten Kendal. Piwulang : Jurnal Pendidikan Bahasa Jawa, 8(2), 107115. https://doi.org/10.15294/piwulang.v8i2.33494.

Hidayah, N., \& Rohmatillah, R. (2021). Pengembangan Buku Cerita Bergambar Islami Berbasis Pendidikan Lingkungan Hidup untuk Pembelajaran Membaca di SD/MI. AR-RIAYAH : Jurnal Pendidikan Dasar, 5(1), 27. https://doi.org/10.29240/jpd.v5i1.2668.

Hidayat, A. (2017). Peningkatan Aktivitas Gerak Lokomotor, Nonlokomotor Dan Manipulatif Menggunakan Model Permainan Pada Siswa Sekolah Dasar. Jurnal Pendidikan Jasmani Dan Olahraga, 2(2), 21. https://doi.org/10.17509/jpjo.v2i2.8175.

Izzaty, R. E., Cholimah, N., \& Wulandari, R. (2017). Pengembangan Buku Cerita Tematik Sebagai Media Pembelajaran Pengenalan Membaca Pada Anak Prasekolah. Jurnal Pendidikan Anak, 3(2). https://doi.org/10.21831/jpa.v3i2.11704.

Jundu, R., Jehadus, E., Nend, F., Kurniawan, Y., \& E. Men, F. (2019). Optimalisasi Media Pembelajaran Interaktif dalam Meningkatkan Kemampuan Matematis Anak di Desa Popo Kabupaten Manggarai. Jurnal Pengabdian Kepada Masyarakat, 10. https://doi.org/10.26877/e-dimas.v10i2.3353.

Misnawan, I. W. (2020). Model Pembelajaran SQ3R Berbantuan Buku Cerita Meningkatkan Keterampilan Membaca Siswa. Jurnal Ilmiah Pendidikan Profesi Guru, 3(2), 282. 
https://doi.org/10.23887/jippg.v3i2.28266.

Nasution, N., Yaswinda, Y., \& Maulana, I. (2019). Analisis Pembelajaran Berhitung melalui Media Prisma Pintar pada Anak Usia Dini. Jurnal Obsesi: Jurnal Pendidikan Anak Usia Dini, 4(1), 240. https://doi.org/10.31004/obsesi.v4i1.311.

Novitasari, Y. (2018). Analisis Permasalahan "Perkembangan Kognitif Anak Usia Dini". PAUD Lectura: $\begin{array}{lllll}\text { Jurnal Pendidikan Anak Usia } & \text { 82-90. }\end{array}$ https://doi.org/10.31849/paudlectura.v2i01.2007.

Nur Hidayah, A., \& Nurhadija, N. (2018). Aktivitas Mendongeng Menggunakan Media Audio Visual Dalam Pembelajaran Moral. Jurnal Smart Paud, 1(1), 73. https://doi.org/10.36709/jspaud.v1i1.3523.

Nurfazrina, S. A. (2020). Analisis Kemampuan Empati Anak Usia 5-6 Tahun (Literature Review). Jurnal PAUD Agapedia, 4(2), 285-299. https://doi.org/10.17509/jpa.v4i2.30447.

Palenkahu, N. (2018). Kecerdasan Linguistik Anak Usia Dua Tahun Tujuh Bulan. Jurnal Pendidikan Dan Kebudayaan, 13(65), 268 - 286. https://doi.org/10.24832/jpnk.v13i65.336.

Pratiwi, N. L. M. T. (2017). Pengembangan Buku Cerita Anak Dengan Menginsersi Budaya Lokal dalam Tema Kegemaranku Untuk Kelas I Sekolah Dasar. Jurnal Ilmiah Pendidikan Dan Pembelajaran, 1(1), 38-47. https://doi.org/10.23887/jipp.v1i3.11984.

Purnamasari, Y. M., \& Wuryandani, W. (2019). Media Pembelajaran Big Book Berbasis Cerita Rakyat untuk Meningkatkan Karakter Toleransi pada Anak Usia Dini. Jurnal Obsesi : Jurnal Pendidikan Anak Usia Dini, 4(1), 90. https://doi.org/10.31004/obsesi.v4i1.273.

Resti Aulia, B. N., \& Budiningsih, C. A. (2021). Tingkat Pemahaman Guru Taman Kanak-kanak di Lombok dalam Stimulasi Pengembangan Bahasa Anak Usia Dini. Jurnal Obsesi : Jurnal Pendidikan Anak Usia Dini, 5(2), 2259-2268. https://doi.org/10.31004/obsesi.v5i2.1082.

Ruiyat, S. A., Yufiarti, Y., \& Karnadi, K. (2019). Peningkatan Keterampilan Berbicara dengan Bercerita Menggunakan Komik Elektronik Tematik. Jurnal Obsesi : Jurnal Pendidikan Anak Usia Dini, 3(2), 518. https://doi.org/10.31004/obsesi.v3i2.256.

Setiantono, T. (2012). Penggunaan Metode Bercerita Bagi Anak Usia Dini Di PAUD Smart Little Cilame Indah Bandung. Jurnal Empowerment, 1(2), 18-23. https://doi.org/10.22460/empowerment.v1i2p18-23.611.

Sumaryanti, L. (2020). Menumbuhkan minat baca anak MI / SD dengan media buku bergambar seri. Journal Basic Of Education, 4(2), 173-183. https://doi.org/10.24269/ajbe.v4i2.2699.

Surachman, D. (2020). Efektifitasnya Untuk Meningkatkan Hasil Belajar Bahasa Indonesia Siswa Sekolah Dasar. Jurnal Gema Wiralodra, 11(2), 180-189. https://doi.org/10.31943/gemawiralodra.v11i2.99.

Tanfidiyah, N., \& Utama, F. (2019). Mengembangkan Kecerdasan Linguistik Anak Usia Dini Melalui Metode Cerita. Golden Age: Jurnal Ilmiah Tumbuh Kembang Anak Usia Dini, 4(3), 9-18. https://doi.org/10.14421/jga.2019.43-02.

Ulwiyah, I. (2019). Pengaruh Story-Reading (Buku Bilingual) terhadap Perkembangan Kecerdasan Linguistik Anak Usia Dini. Journal of Elementary School (JOES), 2(2), 40-49. https://doi.org/10.31539/joes.v2i2.949. .

Vera Sardila, M. P. (2015). Strategi Pengembangan Linguistik Terapan Melalui Kemampuan Menulis Biografi Dan Autobiografi : Sebuah Upaya Membangun Ketrampilan Menulis Kreatif Mahasiswa. Jurnal Pemikiran Islam, 40(2), 110-117. https://doi.org/10.24014/an-nida.v40i2.1500. 